\title{
Feminists at Work: Organizational Leadership in Academic Libraries
}

Freeda Brook, MLIS, MPA

Acquisitions and Resource Management

Librarian

Preus Library, Luther College

fbrook@luther.edu

Pronouns: she/her/hers

\author{
Martinique Hallerduff MLIS, MA
}

Associate Professor, Library Coordinator of Information Literacy

Oakton Community College mhallerduff@oakton.edu Pronouns: she/her/hers

This is a preprint of a published work. Published version citation:

Brook, F. and Hallerduff, M. (2020), "Feminists at Work: Organizational Leadership in Academic

Libraries," Hines, S.S. and Ketchum, D.H. (Ed.) Critical Librarianship (Advances in Library

Administration and Organization, Vol. 41), Emerald, pp. 41-64.

https://doi.org/10.1108/S0732-067120200000041004 
Feminists at Work: Organizational Leadership in Academic Libraries

\begin{abstract}
Feminist leadership in libraries is an emerging area of interest. Distinct from traditional leadership or female leadership, it includes such values as critiquing systems of oppression, valuing whole people, empowering individuals, and sharing information. Here we ask, what do feminist academic library leaders $d o$ ? And can academic libraries operate as sites of resistance to systems of oppression? We surveyed 55 people and conducted 23 semi-structured interviews with library leaders focusing on how they enact feminist values in the workplace. In this chapter, we explore several key themes that emerged through our research: how library leaders specifically advocate for their staff and users, how organizational structures support or resist feminist leadership, and how decision-making functions in their organizations. While there is no single way to be a feminist leader, we discuss the varied ways our participants enact their feminism, from day-to-day words and actions to larger initiatives and programs. As to whether these libraries are functioning as feminist organizations and able to resist or even change dominant oppressive systems of power, the results are unclear. The culture of the parent institutions seems to be a decisive factor in how academic libraries operate, and none of our participants report success at fully breaking away from those norms. Yet our participants also demonstrate how they have sidestepped or even changed official policies to be more inclusive and flexible. In this chapter we present clear examples of feminist values enacted in academic libraries as well as direction for further research.

Keywords: feminist leadership, academic libraries, feminist organizations, academic library management
\end{abstract}




\section{Introduction}

The field of librarianship has long investigated women-in-management, but has only just begun to explore what feminist management might look like in academic libraries. There is not yet a universally accepted definition of what feminist management or feminist leadership means, in part because there are varying definitions of feminism itself. As self-defined feministlibrarians working in leadership positions, we (the authors) are driven to investigate these questions in order to guide and inspire our own daily work. Our project is to understand what organizational leaders ${ }^{1}$ in academic libraries who identify as feminist $d o$, and if, through their actions, an academic library can operate more critically than its parent institution. We spoke with 23 organizational leaders in academic libraries who self-identify as feminists and put these and other questions to them. Beyond these qualities of a shared field, organizational leadership responsibilities and a feminist identity, our participants represent a great deal of diversity in terms of how they define and enact feminism, their positions and institutions, and a variety of identity factors. For the purposes of this chapter, we focus on their broad concerns with advocacy and sharing power.

Participants spoke to advocacy in terms of advocating for people from marginalized populations including library users, students, and library staff ${ }^{2}$. This advocacy work often includes prioritizing the full human experience of library staff in terms of work-life balance, caregiving responsibilities, and awareness of the unique identities, and experiences of people with marginalized identities. They speak to advocating for the individual career growth and

\footnotetext{
${ }^{1}$ Broadly, people who have some kind of leadership responsibility within a library organization, including supervisory and programmatic

2 NB: Unless otherwise specified we will be using the term library staff in an inclusive sense, including all library faculty, clerical staff, administrative staff, and student workers.
} 
opportunities for women and others from marginalized populations as an outgrowth of their feminist values. They discuss frustration with an inability to make change relative to bureaucracy or their relative lack of power, successful changes they've implemented, and individual changes that may subvert official guidelines or policy.

Participants discuss their value of sharing power with others in a variety of ways related to communication, decision-making, flattening hierarchical structures, making information transparent and accessible, and subverting policies created by those perceived to have more power in the interest of their feminist values. Relative to sharing power, participants discuss establishing codes of conducts and meeting norms, working towards consensus, and specific practices around sharing information. They acknowledge that these methods often require more time than methods that prioritize efficiency and are common in traditional management scenarios that emphasize a hierarchical structure.

\section{Literature Review}

Much of the material that examines feminist organizations and leadership looks at the history of and current models within feminist organizations or those organizations born from the 2nd wave feminist movement, including consciousness-raising groups, rape-crisis shelters, and women's health centers, which explicitly grew from these efforts (Calas \& Smircich, 1996). There is also a great deal of work that examines women-in-management, but does not explicitly look at feminist ways of managing (cf. Bate \& Taylor (eds.) 1988; Helgesen, 1995; Karpowitz \& Mendelberg, 2014). Within the Library \& Information Science (LIS) field, studies of leadership and organizations tend to draw from traditional (e.g. non-feminist, non-critical) organizational studies, management studies, and psychology, with the notable exception of the 2017 book, Feminists Among Us: Resistance and Advocacy in Library Leadership edited by Lew and 
Yousefi. We drew on sources from all of these areas to help ground and contextualize our research and findings. We will discuss the main sources here, as well as refer to selective texts in our discussion below.

While there is not an existing set of codified practices or values a leader must practice or believe to be considered feminist, our literature review suggests that there are qualities of feminist leadership that are generally agreed upon. Some of these are that feminist leadership is inherently political, because it seeks to disrupt the status quo and/or intervene in a system supported by and that supports capitalist, heteropatriarchal systems; that feminist leadership recognizes women as an oppressed, subordinate group; and that feminist leadership is concerned with the human experience of its workers either alongside or in opposition to traditional business concerns like profits and efficiency (Calas \& Smircich, 1996; Martin, 1990; Nickel \& Eikenberry, 2006). These two concerns are often in opposition to one another. Ashcraft (2000) describes this as "feminist scholars concur on a fundamental flaw of bureaucracy: impersonality." (p. 348).

Several sources agree that feminist leadership must counteract an approach to work and management which suggests that the workplace and management are natural, neutral, and unchangeable. These "traditional" practices insist that the individual must change to accommodate the environment and feminist leadership suggests otherwise. Fournier and Grey (2000) and Nickel and Eikenberry (2006) argue that "work" is not a natural state that simply exists and cannot be changed. Fournier and Grey suggest "in mainstream management theories various imperatives are invoked (e.g. globalization, competitiveness) to legitimize a proposed course of action and to suggest (implicitly or explicitly) that 'there is no alternative'." (p. 15). "Neutral" management theories suggest, for example, that stressed workers (or managers) must 
find ways to cope with the stress brought on by, for example lack of a work-life balance and care-giving responsibilities competing with work time, unclear expectations, low salary affecting the material circumstances of one's life, or the experience of overt or covert sexism, racism, and other forms of oppression enacted on individuals at work. The expectation for an individual to "cope" as opposed to the institution being revolutionized, is emblematic of a system that views the workplace, work in general, or the institution as natural and neutral and the individual as changeable (Nickel \& Eikenberry, 2006).

Martin (1990) asks "What are feminist organizations?" and frames them according to ten dimensions: feminist ideology, feminist values, feminist goals, feminist outcomes, founding circumstances, structure, practices, members and membership, scope and scale, and external relations. She notes that there are a wide range of feminist organizations, and that there is no single litmus test to define an organization as such. The second dimension, feminist values, seems like one of the most salient aspects to explore for our purposes, which Martin defines as "normative preferences that are invoked as guides to goal formation, action, planning, policy making" (p. 193) and as such, distinct from goals, etc. According to Martin, feminist values (in terms of an organization) include:

...egalitarianism...cooperation....nurturance....peace...the primacy of interpersonal relationships; empowerment and personal development of members; building of selfesteem; the promotion of enhanced knowledge, skills, and political awareness; personal autonomy; and the politics of gender...conceptualize service as a social relationship rather than a technological transfer of expertise, and the sharing of technology and information through a self-help rather than expert-naive recipient format... [and] internal democracy (p. 192) 
Martin indicates that a society must change, based on these values, to become less violent and more supportive of women.

Also relevant to our research is the question of the structure and practices of organizations, and there is some debate within feminist scholarship over the nature of bureaucracy. Ashcraft (2000) defines bureaucracy as "characterized by hierarchy of authority, division of labor, technical qualifications for hiring and promotion, formalized rules and procedures for behavior, and/or impersonal relationships" (p. 349). For some, who could be considered liberal or reform feminists, the project of feminism within an organization is to overcome sexism and advance women within the existing structure (cf. Eisenstein, 1995). In contrast, radical (or revolutionary) feminists view "bureaucracy as inimical to a feminist stance" (Ashcraft, 2000, p. 350). There is a further question of how realistic or effective non-hierarchical organizing is. Martin (1990) notes that "as an ideal type, feminist organizations are depicted as having collectivist internal structures, although relatively few do so "(p. 195). She notes that some people recognize that power within an organization can be used "for people as well as against them" (p. 196, emphasis original).

Acker, in her chapter "Feminist Goals and Organizing Processes" (1995), explains that feminist organizing often starts with democratic decision making but the effort and time this takes may make participation difficult for those with other responsibilities (she notes caregiving in particular), and organizations often evolve to include some form of hierarchy--they might move from a participatory democracy to a representative one. She explains that external stakeholders and funders often shape a feminist organization's structure toward hierarchy in order to comply with regulations. She understands, "this pervasive dilemma for feminist organizing is a consequence of relative powerlessness. Organizations of many kinds survive and 
prosper through a supportive and legitimating environment composed of other organizations" ( $\mathrm{p}$. 140).

Within our own field, a substantial portion of LIS leadership studies focus on the characteristics and attributes of leadership, and yet there is little consensus around a definitive set (Wong, 2017; Mason \& Wetherbee, 2004). One aspect of leadership studies commonly deployed in LIS is emotional intelligence (Hernon, 2017; Kreitz, 2009; McKeown \& Bates, 2013). Emotional intelligence consists of four domains: self-awareness, social awareness, selfmanagement, and relationship management. Other leadership frameworks that have been reviewed include transformational leadership, multicultural leadership, and resonant leadership (Hernon, 2017; Kreitz, 2009). Wong (2017) found several studies that developed their own lists of leadership knowledge, skills, and abilities, but she also noted that much of the literature in this area comes from personal reflection or observation, which makes it difficult to apply the insights or extrapolate to the wider LIS community. She identifies three commonly discussed leadership traits in this literature: communication skills, being a visionary, and being trustworthy.

While it is relatively recent, Feminists Among Us, (Lew \& Yousefi, 2017) now serves as the foundational text examining feminist leadership in libraries. In conducting our research, we have used its chapters as insight into how our field is beginning to make sense of feminist leadership and as a point of departure to shape our own research where we identified questions after examining the contents.

Fleming and McBride (2017), in their chapter "How We Speak, How We Think, How We Do," suggest an essential piece of feminist leadership starts with leading both "intersectional conversations" and "anti-oppression work" (p. 118), because "the most impactful feminist actions in libraries would address not only issues of sexism, but also issues of race, homophobia, 
and other oppressions" (p. 108). They make a strong, coherent case for why this work is needed, rooted in the unchanging whiteness of our oppression and its frequent "remedy" which is increasing the numbers of "diverse" librarians while failing to address the white supremacy (and other oppressive world-views) embedded in the dominant culture that shapes our profession.

Robertson, in her interview with Bourg, engages with many of these ideas (“A Feminist Among Us", 2017). Throughout the interview they have an extensive discussion of the humanity of workers and users, and Bourg describes feminist leadership as (in part) "trying to create an organization where people feel comfortable and welcome as their whole authentic selves" (p. 174). She describes feminist leadership as a "participatory style of leadership" (p. 186), as slow leadership, where communication, agency, and transparency are priorities.

Perhaps most relevant to our current project, Hathcock and Vinopal (2017) sought to explore "what makes leadership feminist?" (p. 147) through interviews with eleven people in library leadership, including people in organizational leadership positions and positions of influence in the LIS field at large. Their interviews coalesced around feminist leadership as "the ability to acknowledge one's own power and use it to advance explicitly feminist values that benefit others" (p. 168). Some specific venues for this work in libraries included community building, creating safe environments, valuing diversity, empowering others, and information sharing.

\section{Methodology}

Our research project involved an initial survey, followed by in-depth interviews. The survey consisted of ten questions, primarily self-described professional and demographic information regarding the individual's role in their institution and their leadership and management responsibilities. It also included the open-ended question, "In a couple sentences, 
please describe how feminism informs your organizational strategy or management style." We used responses to this question to identify 23 themes among practitioners, which in turn informed the questions we designed for the interviews. We sent the survey out on relevant professional listservs and through social media channels. Fifty-five people fully completed the survey.

For the interviews, we recruited participants through several means. We invited survey respondents to participate or to recommend additional names. We also invited librarians who have published on the topic of feminism and library leadership and were in organizational leadership positions. We sought self-identified feminists who work or worked in leadership positions in academic libraries. Beyond those parameters, we wanted to ensure the greatest diversity of perspectives and experiences, especially for the interview participants. We asked participants to self-describe their demographic information, rather than provide a series of predetermined check boxes. Because of this, we decided to report all the categories they mentioned, understanding that this list is neither complete nor exhaustive (e.g. only two people included their status as a parent, but most likely more of our participants are parents). We interviewed 23 individuals, and they claimed the identities listed in Table 1.

\begin{tabular}{|l|l|l|}
\hline White or Caucasian - 19 & Bisexual - 2 & Non-Christian - 1 \\
African American or Black - & Queer - 2 & Jewish - 2 \\
2 & Cisgender - 13 & Agnostic - 1 \\
Asian -1 & Genderqueer - 2 & Buddhist - 1 \\
Chinese descent - 1 & Married - 1 & Atheist - 1 \\
Female - 19 & Parent/Mother - 2 & Middle class - 1 \\
Male - 1 & Has mental illness - 1 & Gen X - 1 \\
Heterosexual or straight - 17 & Able-bodied - 2 & First generation college \\
Pansexual - 2 & Disabled - 1 & graduate - 1 \\
\hline
\end{tabular}

Table 1: Demographic descriptors of interview participants 
Our respondents also work at a variety of institutions across the United States and Canada and in a variety of leadership positions within those institutions (see Tables 2 and 3).

\begin{tabular}{|l|l|}
\hline Public - 10 & Large - 6 \\
Private - 5 & Mid-sized - 4 \\
R1 - 3 & Small - 1 \\
Research university or college - 8 & Faith-based - 1 \\
Master's granting - 2 & Ivy league - 1 \\
Comprehensive - 3 & Urban - 2 \\
Regional - 1 & Commuter - 1 \\
Community college - 3 & Land grant - 1 \\
& Liberal arts - 1 \\
\hline
\end{tabular}

Table 2: Institutional characteristics of interview participants

Dean or Director - 6

Assistant/Associate Dean or Assistant Director - 2

Department Head - 11

Supervisor - 1

Other - 3

Table 3: Position of interview participants

We conducted semi-structured interviews with all 23 participants using Google Hangouts, Skype, Zoom, and one phone interview. We (the authors) each conducted individual interviews with about half of the participants, based on scheduling and availability. Each interview followed a basic set of questions with room to ask follow up questions or explore certain topics in more depth as the interview progressed. Interviews ranged from 25 to 60 minutes. We transcribed and coded the interviews based on the themes that emerged from the surveys and additional themes that developed through the interviews. In total we identified 57 themes in the interviews. 
Our research methodology was guided by feminist research practices, which is fitting for a study of feminist leadership. Reinharz and Davidman (1992) note that open-ended questions and semi-structured or unstructured interviews are both commonly used feminist research techniques and provide a broader, more nuanced, and valuable perspective on the research subject. They note:

[I]nterviewing offers researchers access to people's ideas, thoughts, and memories in their own words rather than in the words of the researcher. This asset is particularly important for the study of women because in this way learning from women is an antidote to centuries of ignoring women's ideas altogether or having men speak for women. (p. 18) As individuals who could have participated in this study ourselves (we both hold or have held leadership positions within academic libraries), we cannot claim complete objectivity as researchers, but we consider our methodology in keeping with feminist research practices (Reinharz \& Davidman, 1992). For the most part, we did not know our interview subjects personally and had no personal connections to their places of employment. Our professional experiences lend us a greater degree of insight into the practices we are studying, and, we hope, lent a greater degree of trust to our participants. To enhance the sense of trust, we also ensured anonymity to all our participants.

We recognize that there is an inherent power dynamic between researcher and subject, in that we as the researchers have the ability to abstract and construct meaning from these interviews and surveys. Ramazanoglu and Holland (2002) noted the practical and ethical challenges of doing feminist research:

Feminist knowledge is worked out in practical struggles over exactly what people do and do not share in their conditions of existence, but these are also struggles over how, or 
whether, connections can be conceived between ideas, experience and reality. These are not only philosophical and epistemological problems, but also practical matters of research skills and ethical practices. (p. 104)

In light of these challenges, which we discussed frequently throughout this process, we shared with participants verbatim quotes that we intended to use and how and when we planned to describe participants in the study. This enabled us to have a dialogue with our participants after the interviews, and in some sense invite them to join us in these practical struggles.

\section{Understanding Feminism}

In conducting our study, we had to consider what it means to be a feminist. We looked to bell hooks, who problematizes feminist as an identity because, "any woman who wants social equality with men regardless of her political perspective (she can be a conservative right-winger or a nationalist communist) can label herself feminist" (hooks, 1984, p. 23). For this reason, hooks suggests we talk in terms of advocating feminism rather than a feminist identity and we agree that this is a useful distinction. She outlines some of the reasons people may not identify as a feminist, including uncertainty about the meaning, the term's association with white women in particular, the term's association with lesbian women, or a general resistance to political identification. Taking this into account, we still sought participants who identify as feminist. The reasons for this choice include: our interest in how this self-identity shapes management practices, recruitment of participants outside our personal networks which necessitated a selfidentification, and to avoid making ourselves the arbiter of feminism or feminist leadership. In recruiting participants based on self-identification, we gathered a group of people from across the 
field with varying perspectives on feminism. We interpreted our participants' definitions of feminism, and observed three distinct groups: reform feminism, revolutionary feminism, and advocacy feminism.

\section{Reform Feminism}

Definitions of reform feminism tend to involve "women gaining equality with men in the existing system" (hooks, 2015). Calas and Smircich (1996) label this "liberal feminism" and trace it to 2nd wave feminism, which aimed for "equal access and equal representation" for women though it "seldom acknowledged that the 'ideal society' and 'ideal humanity' are modeled after Eurocentric, elite, masculinist ideals"(p. 222). Eight participants discussed a feminist identity that could be compatible with this understanding of feminism. Some of the ways this is discussed is "[feminism is] the idea that women have as much or more to contribute to all aspects of society as men have had, but have not had the same opportunities and I think it's kind of a movement to right that inequality," "equity among sexes and genders--political, social, economic equity," "for me right now it means being kind of cognizant of gender inequalities, whether that is in the workplace or just in the world, and working in small ways I would say to keep the playing field as level as possible."

\section{Revolutionary/Intersectional Feminism}

Revolutionary feminism, as understood by bell hooks is a movement that "wanted to bring an end to patriarchy and sexism" and grew out of the experience of working-class, poor, lesbian, and women of color within the feminist movement who understood "that they were never going to have equality within the existing white supremacist capitalist patriarchy" (hooks, 2015, p. 4). Kimberlé Crenshaw, who coined the term "intersectionality" describes this as, "the concept of political intersectionality [which] highlights the fact that women of color are situated 
within at least two subordinated groups that frequently pursue conflicting political agendas." (1997, p. 182) Intersectional feminism draws on critical feminist theory and can be understood as "an approach to analyze the impact of multiple identities in social interaction, ideologies, and institutions and provides an explanation for the influence of structural privilege and oppression and multiple sites of power" (Jones-Johnson \& Johnson, 2014, para 2). Ten participants discuss a feminist identity consistent with intersectional and/or revolutionary feminism. Some of the ways this is discussed include, "for me it's not just about gender equity...I'm an intersectional feminist and I feel like class, race, disability, all that is wrapped up in identities and can't be separated from genders." And, "To me it's about awareness, so Black Lives Matter, and a lot of the minority students, we talk about being woke...so I think about my feminism as embodying my personal experiences with being woke...So every day I get up and it's always there, being a minority, it's always there, being an African American woman, it's there, it's just kind of part of who I am.”

\section{Advocacy Feminism}

Four participants defined feminism as a practice that advocates feminist values or beliefs rather than describe a feminist identity. hooks states that when we separate feminist action from feminist identity, "It implies that a choice has been made, that commitment to feminism is an act of will. It does not suggest that by committing oneself to feminism, the possibility of supporting other political movements is negated" (hooks, 1984, p. 23). Some of the ways this is discussed is "I'm here to remove barriers and navigate the power structures of the organization on behalf of my staff," "it's about creating the conditions...or striving for an ability for everyone to have their own agency to, their own autonomy in life...in an equitable, non-oppressed way," and "feminism is inherently about power. It's about how to navigate and...interrogate power structures, which 
inherently in many cases break down along the lines of like gender and race and identification..."

The range of definitions above inevitably impacts the practices adopted by our participants. All of our participants spoke to how feminism informs their work and described such practices in their interviews. The variety of concerns and strategies reflect the different definitions of feminism along with many other concerns that impact any organizational leader in an academic library including individual personality, relative organizational position, intersecting identities, and institutional culture among others. What follows is an analysis of how their feminist values are enacted through advocacy and care of library staff and users, academic library structures, and decision-making practices.

\section{Advocacy and Care}

Our interviewees speak directly to advocating for work-life balance, meaningful work, and an affirming and equitable workplace culture. This advocacy extends into the library's physical space generally, and particularly towards gender-inclusive bathrooms, the presence of security guards, and physical accessibility. Another area of concern for many participants is advocating for the career growth, recognition, and equitable compensation, particularly for people with marginalized identities and women. Interview participants describe working to make changes to the culture, policy, space, or experience of library staff both through official channels and intentionally subverting or sidestepping these channels.

Much of the discussion of work-life balance among our interviewees focused on caregiving responsibilities:

One of the longest standing things I've done in the libraries that I think definitely comes from sort of a feminist practice is...ensuring that the workplace is a place where people 
realize that they and their personal needs and their family needs and their life is paramount and work is just work...where women aren't penalized for taking maternity leaves, where men are given the license to take parental leaves, where you don't have different expectations for different employees based on what their caregiving role is.

I don't send any emails to people in my department after 5:00 on weekdays or on the weekends...except very very rarely... So, I just, I try to leave people alone when it's not work hours. That... was just sort of really necessary for me at the time that I started here because I had a small child ...just a year old and took up most of my non-work time. So, I was just like I'm done, I'm going home to the baby and that's that.

One participant discussed their support of work-life balance by working to change the culture around personal milestones and moving away from only celebrating "reductionist" and "patriarchal" milestones:

If you were a woman and you had a baby, you had a baby shower and you were reduced to the role of mother and oh how cute. And if you were a male and had a baby, we maybe said congratulations. And that's where it stopped. You know that's bad enough, but then what about people who don't have children? What about people who have other milestones in their life? Sort of taking out this Judeo-Christian heteronormative overlay of our workplace and saying no, no we're going to celebrate other things. We're going to sort of celebrate everything or we're going to celebrate nothing. So, it sort of becomes to celebrate everything. 
To "celebrate everything" as our participant describes above is to bring not-work into work, but doing it in a way that acknowledges what is important to individuals, rather than what is important to a patriarchal society that values traditional gender roles and, in this example, parenthood as life-changing primarily to mothers.

While caregiving responsibilities were a priority to several interview participants, some discuss the latitude they take within their own department to support a work-life balance that may not be explicitly in keeping with HR or other relevant policies: "what I have done and what I have encouraged my supervisors to do is to bend the rules. I don't want to completely violate policy, but to allow people to take care you know of that doctor's appointment that they have to take their mother to or that sick child."

We see a pattern of pushing the boundaries of official policy in other areas in addition to caregiving work, one of which is empowering/allowing people to do work outside of their official job description because it is meaningful to that person. One participant asks, "how can you as a manager advocate for interesting work that's still organizationally relevant... then how can you make space within that work for people's professional goals that are maybe not explicitly served by the institution or by their job description?"

Another participant describes working collaboratively on research with someone she directly supervises who is a union staff member:

We both worked on it at work; he's not technically supposed to, but he got all of his work done with time to spare because he had been doing it for a long time and he's very talented at his job. So, this is kind of like a way for us to get away from the more mundane things... I didn't go around telling people "yeah he's writing a book chapter on work time" because we both would have gotten in trouble. 
Both participants above recognize that the institution or its policies were changeable and made the decision to make changes to the situation based on this feminist value of the whole person.

Unlike other academic units in a college, a library has a defined physical space, and care of this space, is a priority many participants discuss. They believe their space should also reflect feminist values. They discuss gender-inclusive bathrooms, "the bathrooms, making sure that those are...all gender bathrooms--that's a fairly new thing that we've done we've pushed for." One participant mentions lactation rooms:

I'm not opposed to having a lactation space, this is not an issue I'm personally committed to one way or the other, but I certainly understand that this is something that's important to someone and so we should look into it. So, I guess it's you know the old adage that the personal is political.

Another participant contends with the security guard presence in her library, as well as physical accessibility issues:

...the first thing that people see and the last thing that they see when they come in the library is three security guards. Like for people who grew up in an environment where they have ... a contentious relationship with law enforcement or whatever, like that is really not a way to make people feel welcome. The...security guards are really nice and I'm friends with them but they're intimidating just to have them there, like we're watching you kind of. It's not like we're here for you; it's we're here to make sure you don't steal things or...misbehave or whatever. 
...one of our grad students...uses a wheelchair and he has a lot of access issues...our main entrance has a big flight of stairs so we have an ADA entrance below it, but he said he's had to wait up to 20 minutes...ringing the bell for somebody to come let him in. Our hallways...accommodate him, but they're narrow spaces...none of the doors... automatically open. So, I've had a meeting with him in a space where I did meet him outside so I could open the door for him and I just feel like that, I mean, that's got to be really grating for him...I think there's a lot of assumptions made about who is our typical...student or faculty member.

In both of these examples, the interview participant imagines how the affected person feels, clearly demonstrating the value of a person's full, human experience and how library spaces can contribute to dehumanizing, humiliating, or fearful encounters.

Another participant describes an anecdotal measure of the library space as empowering is, "if I see...marginalized patrons using the library feeling safe here, making it a place that they can frequent." How space is used is often determined by how its use is communicated. One participant reflects on this:

Lately we've been having some issues with one of our classroom labs and we've spent a lot of time looking at...what our signs say. How they're either very directive in terms of what you can do and what you can't do in this room. Instead, you know, how do we create the spaces so that they have respect at the center of them, so that people will respond positively and take the action that you want them to as opposed to like challenging them ...Which I don't find to be particularly feminist in its approach. 
Participants describe a variety of methods for making changes to space. Many participants expressed a desire to change the space of the library towards feminist goals, or an awareness of some problematic aspect of the space. Participants expressed concern with libraryas-place specifically because library users include everyone on campus rather than a particular school or group of students. One participant discussed the unique nature of the library-as-place as one of the primary reasons for it being inclusive:

...my library was involved in doing some bathroom renovations and at that time, I thought, oh this is a really great time for us to think about kind of establishing some allgender bathrooms in the library....The library is...a really excellent spot for these things to happen because everyone has access to the library; it's not in a particular department or a particular school, or faculty.

The participant then describes their excitement as they navigate the process of writing a report, conducting research, and meeting with constituents on campus to advocate for this change, but that "the proposal was at that time rejected." In the above example, the participant advocates for change based on feminist values, working within official means to accomplish these goals and is frustrated when the goal cannot be accomplished:

It's an example of doing all the right things...like write a report, all the things you're always told to do, you're advocating, go meet with so-and-so, and there's this idea that if you do the right things and jump through the right hoops...that you will at least get a reasonable decision, but I don't think that's actually the case...It's hard. It's really frustrating. 
This frustration might explain why some participants attempt to advocate outside official channels. For example, another participant discusses the controversy that ensued after the library provided new signage to designate single-use bathrooms in the library as gender-neutral. The University's Board objected to the new signs, and in protest of the board's objection, "I worked with another staff person and we put up...signs over the signs that were there. This bathroom has been freed from the gender binary." Further controversy ensued as these signs stayed up until a "conservative male student posted a video of himself ranting about the signs and tearing them down... and then the original signs got torn down." Library administration became responsible for dealing with the removal of the signs "because of where they are in the hierarchy." Both cases above illustrate the role college or university hierarchies and bureaucracies play when trying to make changes to library space.

In addition to advocating for caregiving, space, and work-life balance, many leaders also spoke to advocating for advancement, pay equity, and recognition. Typically, advocacy is motivated by concerns over disparities in these areas, particularly between men and women. One participant describes advocacy as part of her work "but there is a particular need to look out for those who might not advocate for themselves and more often than not, that's women." In this example, she offered a woman-identified librarian a promotion and the librarian did not ask for a raise. A similar situation had recently occurred with a man-identified librarian who did ask for a raise. In response, the interviewee advocated on the woman's behalf:

I went to talk to my boss to tell her you know this person was receptive to the idea of changing positions, and I said you know what can we do for her in terms of salary? My boss explained to me what the salary band was, which is actually fairly generous, it's 
appropriate, and then I went back to this person and told her this is what we're going to be able to do.

Another participant, a coordinator at a large R1 university, similarly describes the individual work of empowering colleagues to negotiate, "I push colleagues...to negotiate salary and by push, I mean I encourage and provide statistics and talk about it with them." It is important to her to present the information and encourage colleagues, but to be respectful of their comfort level, which she describes below:

I had a colleague, she's receiving an internal promotion...she said, look my salary is everything I want it to be; I'm not going to negotiate. And I said okay, but hold on because your salary is just one component of how you're paid-- do you want to ask them for money for additional training that you might want that you've already expressed interest in, do you want to consider how you get leave and we're a state institution so you can't change that but you can change how you set a culture around flexible time and things like...and she wasn't comfortable negotiating for money and I understood and respected that...and she ended up negotiating for a standing desk.

Both of these examples illustrate advocating for individual change which leaders initiate based on their awareness of feminist concerns about pay inequity and advocacy as empowerment leadership practices. Neither of these participants were in a position to set salary themselves, but used what influence they had to work towards pay equity.

An associate dean-level leader at a private research university similarly discusses her advocacy work, but in terms of recognition rather than salary. She describes a cultural problem 
of women being "put in the position of being required to do all of the work and then in the end they have been taught not to toot their own horn." As part of her advocacy strategy she says, "I think it is the job of leadership to toot it for them, until something changes in the larger culture of this country and potentially the world where women feel it's okay to toot their own horn." In the example she provides, a librarian has done the majority of the work in a community group, but she does not claim credit for it herself:

...but whenever I talk about what the group is doing, because lots of people are interested, I say “ ___ has done all of the work for that. So, if you like it, let me know

and I can put you in touch with ." She's heard me say that, she's never corrected me, so I suspect she has done all of the work.

In this way, she advocates for the librarian publicly in order to recognize her, but at the same time is helping her build her professional network, a type of advocacy likely to have long-term ramifications just as advocating for higher salaries would.

\section{Organizational Structure}

In keeping with the debate within feminist organizational studies, we see a tension between hierarchical organizational models and those with flatter and more egalitarian structures. As discussed in the literature review, while there is a discussion among feminist scholars around the wisdom and viability of this type of organizational model, it is generally seen as the ideal for feminist organizations.

Academic libraries' organizational structures tend to be very hierarchical, mirroring the structures of their parent institutions (DeLong, Garrison, \& Ryan, 2012; Kaarst-Brown, Nicholson, von Dran, \& Stanton, 2004). These organizational structures include top-down, 
centralized decision making, where senior administrators are primarily concerned with strategic direction and coordination and allocation of resources (Alfred \& Rosevear, 2000). Over the past several decades, as funding for higher education has changed along with expectations for greater accountability and assessment, there has been an increased attention to and fascination among higher education leaders with private sector, for-profit business models and processes (Birnbaum, 2000; Kidwell, Vander Linde, \& Johnson, 2000). The same has been seen in academic libraries: an emphasis on change in libraries, along with calls for libraries to become more agile, customer-driven, lean, efficient, forward-thinking, and to demonstrate their value or return on investment to university leaders and the public (Day, 1998; Holloway, 2004; Nicholson, 2015).

In discussing the structures of decision making and power within their institutions, our interview subjects mention the challenges of working in a highly structured, hierarchical environment. One person reflects, "I think there's a problem amongst large research universities and across institutions within ARL and such that the gender representation of those large institutions is predominately male and that doesn't seem to be changing that rapidly." Several people note that the goals and perspectives of those people in leadership, either in the university as a whole or within the library, do not align with inclusive feminist values and are barriers to making positive changes within the organization.

Most interview participants describe flatter organizational structures as desirable, linking them to better communication, transparency, empowered library staff, and better outcomes for library users. One person details a restructuring of the library with the creation of a Libraries Council that included supervisors and coordinators as well as three "at-large" seats chosen at 
random, giving all library staff the chance to participate in the decision-making processes at the organization. The director of a small college library explained their structure:

...we're pretty nonhierarchical, but we have sort of working groups. So, like the instruction and reference folks are a working group, and the technology folks have kind of a working group. So, I feel like if decisions need to be made by those groups of people they will be. Often, they'll just make a decision and then let me know or I'll ask them, "Can you decide something?"

While this type of structure is undoubtedly easier in a small organization, increased information sharing and providing more opportunities for input from all library staff is seen by many of our participants as a way to empower staff. There is also a sense that this leads to better decisions and services for library users.

I think that if those hierarchies were broken down more effectively that means that every person that works in a library could think of themselves an educator. And could truly be an educator. And that would mean that in their own capacity, in their own way, in their own world, and that would mean that students would have an opportunity to learn from an expanded set of perspectives and experiences, which would mean that work would happen, that growth on the part of students, or the people that we serve, would be more authentic, more rich, and more effective.

However, some respondents acknowledge that the flatter structures can have drawbacks or are not necessarily aligned with feminist values. Gathering input from staff can be timeconsuming and inefficient. While efficiency is not necessarily a feminist value, these concerns 
raised by several of our interview participants reflect the practical realities of running academic libraries in today's environment. They also echo the existing debate within feminist organizational scholarship around whether the non-hierarchical ideal is always practical or possible (Martin, 1990). Interestingly, there has also been a move within academic libraries to reduce hierarchical structures in recent years to make libraries more agile and respond better to market forces, not necessarily to create more inclusive institutions (Murray-Rust, 2017; Phipps, 2004).

Even respondents who report that their organizations were very hierarchical find ways to subvert those structural inequities. One example of this is being respectful of staff in an environment that often reinforces a faculty/staff divide where staff are subordinate to faculty or library staff are subordinate to librarians. Someone who manages student workers says that she is careful about what tasks she assigns and to whom. She shows that "I'm willing to also do that work myself, like the grunt work. And I do need to delegate. At the same time, I try to model I'm not better than you." Another participant, an instruction coordinator at a community college, says that she explicitly acknowledges structural power imbalances between administrative/clerical staff and faculty in the library and calls attention to who is and is not a part of decision-making processes. Respondents mention their own efforts to be reflective about their own power, and one respondent in a middle management position questions whether trying to change things from within management was the most effective approach: "Maybe my energies are better spent in my union as opposed to at management tables, I don't know."

Very few of our participants describe widespread projects to restructure their libraries around collectivist or flat structures, which speaks to one of our core research questions. Is it possible for academic libraries to forge non-hierarchical, feminist structures within their larger 
institutions? Can we change oppressive structures and cultures from within? Our respondents also grapple with these questions.

Whatever issues--positive or negative--that are in the broader institution, I think to some degree are reflected in departments, support services, and the library. So how much, in terms of feminist practices and changing the way libraries operate, is going to bump up against the larger institution?

Organizational cultures and structures can be opaque. Cultures are often seen as "natural", invisible, and unchangeable by those operating within them, making the feminist project of change more challenging (Fournier \& Grey, 2000; Nickel \& Eikenberry, 2006). These ideas repeatedly come up in our interviews, for example:

...what I think happens too much and happens in almost every organization I've ever worked in is that the culture of the organization is solidly in the hands of an elite. They're elite either by dint of position or years of service or both. And the new people in the organization are asked to bend themselves to that culture, rather than asked, how can we do better?

...not that there are not institutional barriers but that the institutional barriers themselves are often obscured in the sense that they're not recognized [by] the institutional folks who are in position to change those barriers. And that folks who are impacted by those barriers are often put in the position of having to educate senior leadership about those barriers, that they even exist. And then once there is hopefully a recognition that they exist, how to address them.

Our participants recognize the difficulty of changing organizational culture, especially without buy-in from those in senior leadership positions. None of our participants relate examples of 
changes to library structures or culture that subverted or went against the norms of the larger parent organization, suggesting that this is an unlikely, if not insurmountable challenge.

\section{Decision Making}

Structure is closely related to, and in some ways defines the decision-making processes within organizations. Alongside hierarchical structures, traditional decision making tends to be patriarchal: concerned with control, efficiency, clearly defined roles and duties, with power emanating from the head of the organization. These same values frame many decisions as competitive and conflict-driven, suggesting scare resources and zero-sum outcomes (Wicks, Gilbert, \& Freeman, 1994). In contrast, Rusaw (2005) identifies pluralistic leadership as a central theme of feminist organizational theory: "collaborative, interpersonal relationships that aim at higher social purposes. Power emanates from consensus rather than from being the means for achieving consensus" (p. 389). While consensus is not the only mechanism for pluralistic decision-making, it is often seen as an ideal and frequently mentioned in connection with feminist ethics and decision-making (Burton \& Dunn, 1996; Rusaw, 2005; Wicks, Gilbert, \& Freeman, 1994). Communication is also essential to collective decision making. Wicks, Gilbert, and Freeman state, "Communication provides the mechanism for persons to interact with and learn from one another, to build trust, to find points of agreement and disagreement, to discover how a relationship can enrich each party involved, and to sculpt a form of interaction that fits them" (p. 487). In this way open, transparent communication can be seen as an essential component of feminist decision making.

Our participants describe a range of decision-making practices, among different institutions and in different contexts within the same institution. While several people mention 
consensus as an ideal or something to work towards, two participants discuss how and when they employ consensus-based decision making. An instruction coordinator at a community college describes weekly meetings among the small group of faculty librarians:

Sometimes it's majority rule and sometimes it's consensus. I think if one member of the faculty feels profoundly uncomfortable with something, we won't do it. So, in that sense it's a true consensus. But lots of times the decision comes down to how many of us think this is a good idea? Are the people who think it's a good idea willing to put more work in? Okay fine, everyone's okay with that. In a way that's a form of consensus too. So, yeah, I think that's what I mean by collective decision making. Discuss and discuss and discuss until most of us feel pretty okay with the decision and then we record it and move forward from there.

But she also noted the complex power relationship between the administration and the faculty: Well, I guess there's a tension between whether she [the dean] always has veto power over decisions and the fact that our faculty contract usually dictates our work and not her. And so, there is something that she will make a decision about that it turns out she doesn't get to make a decision about, because we're faculty, and that means there is some stuff that she can't make us do. When it comes down to it, often there's a conversation, which means that our union representative on our library staff...will say something like, "Well, I have to look at the contract to see if you can tell us we have to do that or not."

In this example the space and conditions for consensus-based decision making are in some ways defined by the hierarchical and contract-based power structures of the institution.

The process of building consensus and creating change is time-consuming and slow, as several of our participants note. Decision-making that's collaborative, builds consensus, or 
carefully solicits multiple voices takes more time than top-down hierarchical decision making. The associate dean at a Master's granting university discusses her efforts to clearly define the terms of decision making at her library, including a deliberate effort to slow the process down:

So, I found myself in meetings taking time to verbalize... "here's what we're going to do: we are going to listen to the different points of view, we're not going to rush to judgment right now and we're going to build consensus now"...I found myself saying things like, "we're going to set some ground rules about how we engage, about how we disagree, about our responsibilities."

She also describes the work she does before and after meetings to discuss initiatives with people, the "groundwork" that is necessary to make this kind of decision-making work: "I have to get out of the office, I have to be where people are, I have to talk to them.” Another participant specifically links slowness with feminist values: ...those micro kind of day-to-day, how we communicate with others, how we treat them through written emails, or through one-to-one interactions. I think those...probably...consume so much of the energy of applying feminist values to my engagement with my work and with others. And those conversations are I think at the core for me emphasizing a culture of care and a culture of slowness, slowing down, and that's probably where you know my power--its ability to slow things down where necessary and it's never to speed things up funnily enough. And by that I just mean hearing the conversation to just seeing the other person where they are and what they're thinking. 
More of our participants describe forms of decision-making that are not fully consensusbased, but still collaborative or include a wide range of input. Several describe making changes when they took on a leadership role to begin holding meetings with all library staff as a way to share information more broadly and give more people a chance to provide input. Several also mention using "open door" policies for similar reasons. One person puts it simply: "I try to advocate for erring on the side of larger meetings than smaller meetings to include more people." Another makes the clear link between decision making and communication: "we're...thinking about organizational development that leads us toward participatory decision-making and this will help us all in the organization take active responsibility for effective communication.”

Participants are not just concerned with broad input in decision making. For some it is about ensuring underrepresented and marginalized perspectives were present in the process. One person puts it: "I think it comes down to valuing multiple voices for me and underrepresented voices and having equitable and inclusive conversations and decision-making and really expecting a lot from people." Several people also note unequal representation on committees, including by gender, race or ethnicity, or employment status (e.g. clerical staff). This kind of intersectional thinking comes up repeatedly in our conversations, and reflects the sense that in the LIS field, feminism and feminist leadership is more and more being viewed as explicitly intersectional, as in Fleming and McBride (2017), Hathcock and Vinopal (2017), and Robertson (2017).

Several people highlight the importance of defining clear expectations around decision making structures, especially in cases where they were attempting to change established norms. At a large research university, a department head worked with her staff to develop an "operating agreement" that included team norms and expectations, including how decision making would 
work within their unit. Later, after a reorganization and several new people joining the department, they revisited the agreement to update it. A department head at a different research university describes using a similar technique with committees:

I've been trying to establish group norms at the beginning so that we all have a discussion about how we want to work together...I found that is really helpful, because even though, the people who break those norms, it may not be that meaningful for them, it gives the people who are experiencing that aggression or whatever a chance to point to something like, "oh, actually we agreed that we're going to do it this way."

Even in a consensus-based environment, clear expectations and structures can be important. An instruction coordinator describes this process:

Before we tell our colleagues what to do in relation to our coordinator responsibilities, [we] formulate a set of a questions to ask our colleagues: giving a context, and then creating enough space to have a conversation where we decide together what the work will be. What the work will be, how the work will proceed, and whose responsibilities that work will be. And what that's meant is that that work is no longer limited by one person's imagination. And it has also meant a more equitable distribution of labor. Here the defined expectations of decision-making lead to better outcomes.

Across many examples and contexts, our participants emphasized the need for transparent and clear communication, regardless of who holds the final decision-making power. This is often linked to the idea of including more people in the decision-making process: "I feel like even if it's only for 20 minutes, just so that we can all sit together, so that we can all hear from each other what's going on in our areas and share any information that needs to be shared." Another person, operating in a more hierarchical environment, suggests: 
So, I do think that's important to have people in decision-making capacity who feel like they can just do that when they have to. But I think...soliciting information from the people on the ground actually like working within library policy and then actually acting on that information would go a long way toward...empowering those of us who aren't the top of the hierarchy. Even if there still is one--just having it function differently.

There is also a danger in making decisions too quickly or without the requisite information: "But then there's also the 'let's just make a decision and get on to the next thing' without really understanding what the issues are or making sure that again everyone knows exactly where we are what we're talking about." In these ways our participants link open communication with slow and collective decision-making processes.

Not everyone we interviewed sought collective or consensus-based decisions in all settings. Two participants mention that some hierarchy is necessary in order to make decisions efficiently. Others struggle with the right balance: "I feel like I am constantly trying to walk the line between transparency and [too much] information." One has had experience in a feminist organization in the past which informs her approach as a library leader:

And I have been lucky enough long ago to be part of working at a women's shelter that used a collective model which is pretty rare but it was amazing to see like, okay everybody makes decisions together. Most people don't get that experience. I loved it but it was really really time consuming. Is that something that--and I'm not the boss here of everything--so I don't think it's realistic to really consider a model like that here, but I feel like to be truly at the spirit of feminism you would be looking more towards those sorts of models. 
Here the participant acknowledges the tension between feminist values and the practical realities of running a library. Perhaps even more illustrative of this tension is when our participants describe specific decisions they made either on their own or contrary to what their group would have decided, but which were in support of other feminist values. One was a decision to go with an open source software system for the library, consciously resisting capitalist market forces that are pressuring libraries. She acknowledges:

So that was interesting because the decision was not, probably not as collaborative as I would have suggested for a lot of other decisions that we make in the library. This was a decision that I informed other people and I let them know why we're doing this and I gave all the rationale, all of the financial rationale, but I talk about it in terms of a values-based political move that is important for our sector and for our students and for all the things that I'm seeing is happening in the marketplace.

Another describes making a unilateral decision in programming: "So this year I have kind of taken, not control precisely, but I started to steer the direction of our next hackathon." She described how in the past the annual event was too technically focused, unintentionally excluding potential users. Under her leadership, she chose a topic and framed participation in broader, more welcoming terms. These examples bring to light some of the inherent and unavoidable conflicts that arise for feminists operating within the hierarchical, heteropatriarchal, and capitalistic grounds of higher education.

\section{Conclusion}

Our research details what feminist academic librarians $d o$, based on their feminist values and demonstrates that there are many ways to practice feminism. They often seek consensus and 
value a broad base of input in decision making, though at times they use their organizational authority to make unilateral decisions based on feminist values. Many of them seek to improve communication and transparency in their organizations, but some suggest we must balance that with the need for efficiency. Many of our participants are concerned with their organization's membership and seek to change structures and practices to make membership more representative in terms of people that are often organizationally or culturally marginalized. Overwhelmingly, they are concerned with the full human-experience of library staff--their worklife balance, caregiving responsibilities, and agency.

Throughout our interviews, our participants described and brought to light a wide range of experiences and practices, not all of which we were able to report in this chapter. In subsequent research we hope to explore the common emotional experience of academic library leaders, which involves both hopefulness and burnout associated with educating others about issues of equity, diversity, and inclusion and holding people accountable for discriminatory behavior and microaggressions. The leaders we spoke with describe this work as draining, but they tend to agree that it is important and motivating at the same time. Because our research has affirmed the value that feminist academic library leaders place on the full human experience of library workers, we feel it is important to address these issues in future writing. Similarly, questions about advancement for academic library leaders are linked with ambivalence about how best to make use of power and effect change, which Nickel describes as "the opportunity to contribute to precisely the system within which one is oppressed" (Nickel \& Eikenberry, 2006, p. 361). Advancement is strongly linked with the emotional and professional experience of leadership and we will investigate this in subsequent writing. 
As to whether academic libraries can operate as feminist organizations, some ideas for how this might be done are presented in this paper and our research suggests that systemic change is possible, but difficult and perhaps unlikely. Many of our participants feel the culture and structure of their libraries are strongly influenced by their parent organizations, and none reported substantive, widespread changes in their library that ran counter to the rest of their campus. The literature suggests this is the project of feminist management, "it is concerned with opposing marginalization and with subordination" and that "a feminist management seeks social change" (Nickel \& Eikenberry, 2006, p. 364). The pull of parent institutions and the industry of higher-education is strong; the stakeholders, budgets, and boards, to which we answer hold a great deal of power. Yet, the leaders that participated in our research demonstrate that it's often possible to sidestep or change official policy to be more inclusive, to create space for traditionally silenced voices, and to create flexibility so that library workers might achieve both meaningful careers and lives outside of work. Such actions, however, rarely address systemic issues, or they do so in isolated ways. Some of our participants suggested that this project of feminist leadership must stretch beyond individual practices at disparate institutions: that it must occur across and throughout the profession in order to succeed. Perhaps if more people shared the values and praxis of the leaders interviewed for this project, and perhaps if our libraries could collectively explore additional ways to make changes based on these values, we could impact systems that currently reflect a dominant culture steeped in white-supremacist, capitalist, heteropatriarchy.

\section{Acknowledgements}


We offer many thanks to everyone who participated in our interviews and survey. Without your willingness to share your thoughts, feelings, practices, and time with us this research would not be possible. We are deeply thankful. Thanks to Mary Hallerduff for her encouragement and the gift of time to pursue this research, which resulted in her doing a large share of parenting and household labor. Thanks also to Jesse Mulert for his unconditional and unflappable support and encouragement throughout the research process. 


\section{References}

Acker, J. (1995). Feminist goals and organizing processes. In M. M. Ferree \& P. Y. Martin (Eds.), Feminist organizations(pp. 137-144). Philadelphia, PA: Temple University Press.

Alfred, R., \& Rosevear, S. (2000). Organizational structure, management, and leadership for the future. In A. M. Hoffman, R. W. Summers, \& D. L. Hubbard (Eds.), Managing colleges and universities: Issues for leadership (pp. 1-28). Westport, CT: Greenwood.

Ashcraft, K. L. (2000). Empowering “professional” relationships: Organizational communication meets feminist practice. Management Communication Quarterly, 13(3), 347-392.

Bate, B., \& Taylor, A. (Eds.). (1988). Women's communicating: Studies of women's talk. Norwood, NJ: Ablex.

Birnbaum, R. (2000). Management fads in higher education. San Francisco, CA: Jossey-Bass.

Burton, B. K., \& Dunn, C. P. (1996). Feminist ethics as moral grounding for stakeholder theory. Business Ethics Quarterly, 6(2), 133-147.

Calas, M. B., \& Smircich, L. (1996). From the "women's" point of view: Feminist approaches to organizational studies. In S. Clegg, C. Hardy, \& W. R. Nord (Eds.), Handbook of organization studies (pp. 218-257). London: SAGE.

Crenshaw, K. (1997). Intersectionality and identity politics: Learning from violence against women of color. In M. L. Shanley \& U. Narayan (Eds.), Reconstructing political theory: Feminist perspectives (pp. 178-193). University Park, PA: Pennsylvania State University Press.

Day, M. T. (1998). Transformational discourse: ideologies of organizational change in the academic library and information science literature. Library Trends, 46(4), 635-667. 
DeLong, K., Garrison, J., \& Ryan, M. (2012). Changing role of senior administrators (SPEC Kit No. 133). Washington, D.C.: Association of Research Libraries. Retrieved from https://scholarworks.gvsu.edu/library books/3

Eisenstein, H. (1995). The Australian femocratic experiment: A feminist case for bureaucracy. In M. M. Ferree \& P. Y. Martin (Eds.), Feminist organizations: harvest of the new women's movement (pp. 68-83). Philadelphia, PA: Temple University Press.

Fleming, R., \& McBride, K. (2017). How we speak, how we think, what we do: Leading intersectional feminist conversations in libraries. In S. Lew \& B. Yousefi (Eds.), Feminists Among Us (pp. 107-126). Sacramento, CA: Library Juice Press.

Fournier, V., \& Grey, C. (2000). At the critical moment: Conditions and prospects for critical management studies. Human Relations, 53(1), 732.https://doi.org/10.1177/0018726700531002

Hathcock, A. M., \& Vinopal, J. (2017). Feminist praxis in library leadership. In S. Lew \& B. Yousefi (Eds.), Feminists among us: Resistance and advocacy in library leadership (pp. 147-172). Sacramento, CA: Library Juice Press.

Helgesen, S. (1995). The female advantage: women's ways of leadership. New York: Doubleday.

Hernon, P. (2017). Reflections on library leadership: An examination of four leadership theories. Library Leadership \& Management, 31(4), 1-12.

Holloway, K. (2004). The significance of organizational development in academic research libraries. Library Trends, 53(1), 5-16.

hooks, bell. (2015). feminism is for everybody. New York: Routledge. 
hooks, bell. (1984). Feminist theory: From margin to center. Boston: South End Press.

Jones-Johnson, G., \& Johnson, W. R. (2014). Multiracial feminism. In S. Thompson (Ed.), Encyclopedia of diversity and social justice. Lanham, MD: Rowman \& Littlefield. Retrieved fromhttps://search-credoreferencecom.dom.idm.oclc.org/content/entry/rowmandasj/multiracial_feminism/0

Kaarst-Brown, M. L., Nicholson, S., Von Dran, G. M., \& Stanton, J. M. (2004). Organizational cultures of libraries as a strategic resource. Library Trends, 53(1), 33-53.

Karpowitz, C. F., \& Mendelberg, T. (2014). The silent sex: gender, deliberation, and institutions. Princeton, NJ: Princeton University Press.

Kidwell, J. J., Vander Linde, K., \& Johnson, S. L. (2000). Applying corporate knowledge management practices in higher education. Educause Quarterly, 23(4), 28-33.

Kreitz, P. A. (2009). Leadership and emotional intelligence: A study of university library directors and their senior management teams. College \& Research Libraries, 70(6), 531554.

Lew, S., \& Yousefi, B. (Eds.). (2017). Feminists among us: Resistance and advocacy in library leadership. Sacramento, CA: Library Juice Press.

Martin, P. Y. (1990). Rethinking feminist organizations. Gender and Society, 4(2), 182-206.

Mason, F. M., \& Wetherbee, L. V. (2004). Learning to lead: An analysis of current training programs for library leadership. Library Trends, 53(1), 187-217.

McKeown, A., \& Bates, J. (2013). Emotional intelligent leadership: Findings from a study of public library branch managers in Northern Ireland. Library Management, 34(6/7), 462485. 
Murray-Rust, C. (2017). Radical restructuring: Library renovations lead to personnel and process reorganization. American Libraries, 48(9/10), 25.

Nicholson, K. P. (2015). The McDonaldization of academic libraries and the values of transformational change. College \& Research Libraries, 76(3), 328-338.

Nickel, P. M., \& Eikenberry, A. M. (2006). Beyond public vs. private: The transformative potential of democratic feminist management. Administrative Theory \& Praxis, 28(3), 359-380.https://doi.org/10.1080/10841806.2006.11029537

Phipps, S. E. (2004). The system design approach to organizational development: The University of Arizona model. Library Trends, 53(1), 68-111.

Ramazanoglu, C., \& Holland, J. (2002). Feminist methodology: Challenges and choices. Thousand Oaks, CA: SAGE.

Reinharz, S., \& Davidman, L. (1992). Feminist methods in social research. New York: Oxford University Press.

Robertson, T. (2017). A feminist among us: An interview with Chris Bourg. In S. Lew \& B. Yousefi (Eds.), Feminists among us: Resistance and advocacy in library leadership (pp. 173-188). Sacramento, CA: Library Juice Press.

Rusaw, C. (2005). A proposed model of feminist public sector leadership. Administrative Theory \& Praxis, 27(2), 385-393.

Wicks, A. C., Gilbert, D. R. Jr., \& Freeman, R. E. (1994). A feminist reinterpretation of the stakeholder concept. Business Ethics Quarterly, 475-497.

Wong, G. K. W. (2017). Leadership and leadership development in academic libraries: a review. Library Management, 38(2/3), 153-166. 
